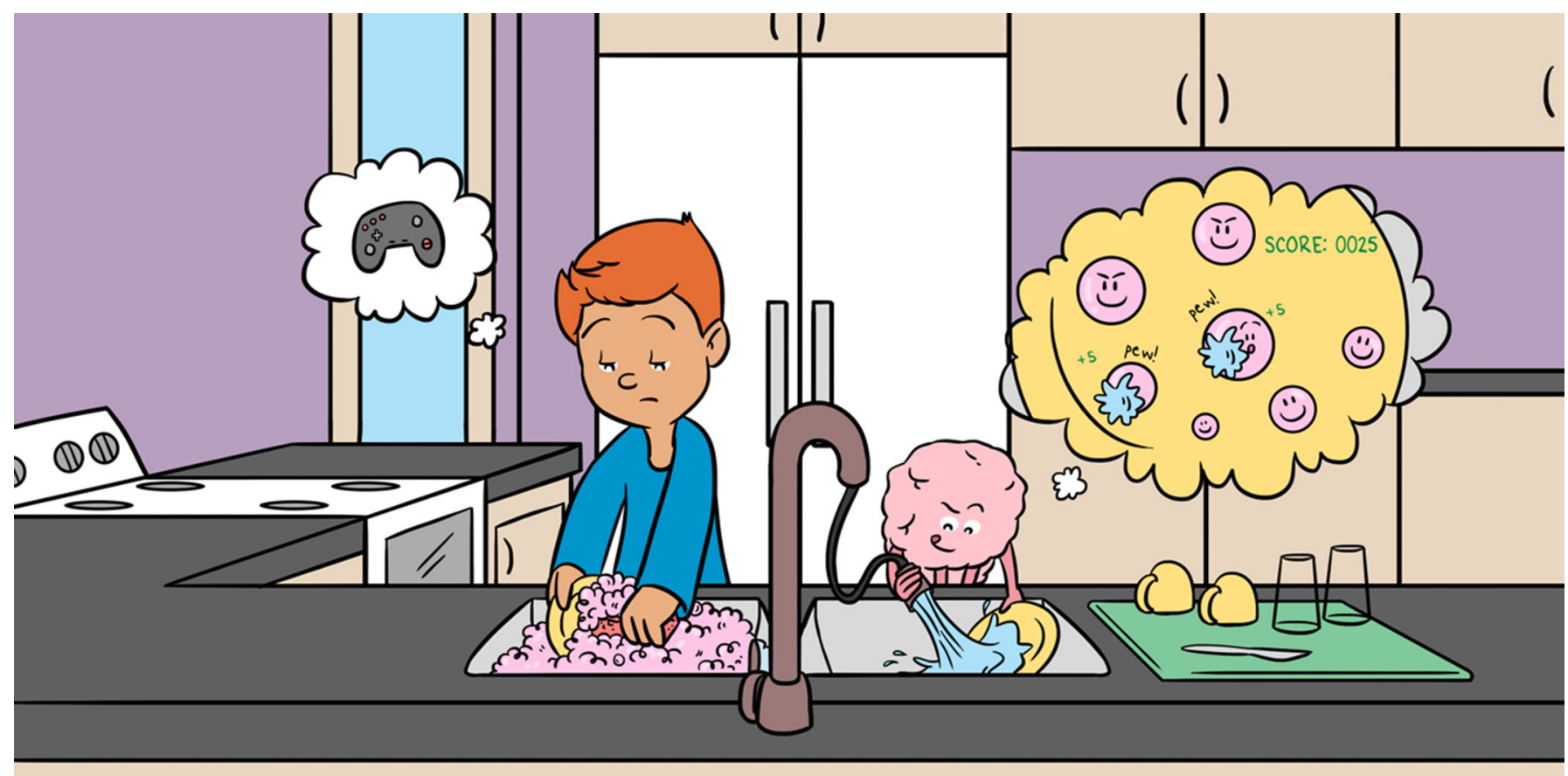

\title{
A BORING OVERVIEW
}

\section{Caitlin Mills * and Catherine McGrath *}

Department of Psychology, University of New Hampshire, Durham, NH, United States

YOUNG REVIEWERS:

ORGANIZATION FOR

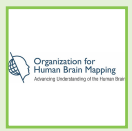

HUMAN

BRAIN

MAPPING

AGES: 8-15

TIAN

AGE: 14
Boredom is a common experience for everyone across the world-no matter how old you are or where you live, you can get bored. Boredom occurs when we are feeling negative and we want to be doing something other than what we are currently doing. Scientists think we may experience boredom as a way to tell ourselves that it is time to move on to something different. What we choose to do next may depend on what we are currently doing; we may choose to do something different based on whether we experience boredom during class vs. at home. Boredom is associated with some negative behaviors, but it may also lead to positive things like more creativity. This article provides an overview of the definition of boredom, who experiences boredom, when they experience it, and what behaviors and brain areas are associated with boredom.

\section{WHAT IS BOREDOM?}

Almost everyone gets bored. The majority of people in the U.S. experiences boredom at least once a day [2]. But what does it mean to be bored? Scientists commonly define boredom as the "experience 
of wanting, but being unable, to engage in satisfying activity" [1]. This definition means that boredom: (1) is a negative feeling, and (2) is experienced when we cannot find something better to do. Boredom occurs so frequently that scientists want to understand why we get bored and what happens when people experience boredom.

This article provides an overview of what scientists think about boredom, including who gets bored, why we experience boredom, and what happens in the brain during boredom.

\section{WHO GETS BORED AND WHEN?}

Everyone across the world gets bored, no matter how old they are, where they live, or what gender they are. People feel bored in all kinds of places: at school, home, or work. One study asked over 3,000 people to rate their levels of state boredom throughout their days during their everyday lives [2]. These scientists found that some groups of people report being bored more often than others. For example, men report more boredom than women, and people who are younger report more boredom than older people. They also found that people feel more bored in certain places and at certain times. People are more bored at school, work, and when they are studying, or spending time with coworkers or strangers. People are less bored when they are with their friends or family, or at a restaurant. People also feel more bored in the afternoon compared to the morning or night. When people get bored, it might be because what they are doing is either too easy or too difficult for them. When what we are doing is too easy or too hard, we may lose interest and have a hard time paying attention. Boredom can also happen when something that used to feel exciting starts to become less exciting.

When our feelings of boredom inspire us to explore new things, those new things can be good or bad. Scientists have found that people who are bored more often may also feel lonely, angry, sad, or worried [2]. Boredom can be more extreme in some cases, like for people with depression or traumatic brain injuries [3]. There is no cure or medicine people can take to be less bored but there are many ways people attempt cope with boredom-some ways may be healthier than others! Boredom may also make it harder to do well on schoolwork. However, it is important to point out that boredom has positives aspects too. Boredom may inspire us to come up with more ideas, be creative, and use our imaginations.

\section{WHY DO SCIENTISTS THINK WE GET BORED?}

When people get bored, they experience a lot of different things. People who are bored feel unhappy. They have a hard time paying attention, and they often think about other things. They can feel tired, 
stuck, and like time is moving slowly. Some scientists think we feel these negative things as a way to send a message to ourselves [4, 5]. The message from boredom is that we do not like what we are doing and that it is time to move on to something different so we can stop feeling bored. Feeling boredom may help us realize that what we are doing is not interesting to us. Boredom may also motivate people to explore new things. When we are doing something that is not entertaining, boredom can motivate us to do something else. You might think of boredom like an alarm. It goes off when we are doing an activity that we do not want to do. Boredom could guide us toward something that we want to do more. It may also help keep us on track with our goals or prevent us from staying stuck on one thing for too long.

Sometimes, when we are bored, we can stop doing what we are doing, and start doing something else. But sometimes we cannot simply do something different. This might happen in the classroom when we are listening to something boring or have to practice writing words over and over. Even though we may be bored, we cannot just get up and leave the classroom without getting into trouble! It is not surprising that people respond to boredom differently depending on what they are doing (in class vs. playing at home). Someone who is bored while watching a movie has more choices than someone who is bored while doing homework.

Some people may also let their minds wander off to different things and rely on their imaginations to entertain them when they cannot escape their boring situations [6]. They may also be able to find more exciting ways to think about what they are doing. A person doing homework has to finish it, so that person may escape boredom by making the homework more exciting, possibly by singing the math problems or creating a mental game involving the homework.

TRAIT BOREDOM

A person's general likelihood of being bored.

\section{HOW DO SCIENTISTS STUDY BOREDOM?}

There are a few different ways scientists typically study boredom. The first one is focused on what is called trait boredom, which is a person's general likelihood to be bored. You can think about trait boredom kind of like a personality type-do you tend to be bored much of the time? Trait boredom is often measured by asking people to fill out a set of questions called the Boredom Proneness Scale [7]. This scale asks people to rate different statements on a scale of 1 (strongly disagree) to 7 (strongly agree). Statements include things like, "time always seems to be passing slowly" or "I often find myself with nothing to do, time on my hands." We are not aware of any studies that have followed the same people throughout their whole lives to see how their boredom changes. However, scientists have found that older people generally tend to report boredom less often [2]. It is possible that a person's level 


\section{BOREDOM}

INDUCTION

An activity that researchers ask people do to make them feel bored. For example, this could be watching a boring video, reading a boring story, or counting for a long period of time.

FUNCTIONAL

MAGNETIC

RESONANCE

IMAGINING (fMRI)

A technique commonly used by scientists to measure brain activity. It looks at changes in blood flow. It is safe and painless.

\section{DEFAULT NETWORK}

A large brain network made up of multiple regions that are typically associated with things like internally-oriented thoughts, mind wandering, and memories about your own life (also called autobiographical memory). of trait boredom may change throughout their life, but other factors probably play a role too.

The second type of research on boredom focuses on state boredom, which is boredom in a particular situation or moment. State boredom is different from trait boredom because everyone can experience boredom at some points in the day, even if they do not tend to be bored all the time. Researchers often study state boredom in a few different ways. One of them is to simply get people to do a boring task. This method is called boredom induction. For example, imagine having to sit and watch a video of people folding clothes over and over-would this make you bored? If you answered yes, that is what most people say. Another method is to ask people to rate their levels of boredom randomly while they complete some task like reading or watching a movie. This method allows researchers to see when and how often people get bored.

\section{WHAT ABOUT THE BORED BRAIN?}

Scientists have also started to look at what happens in the brain when people experience boredom. Most of these studies have used an imaging technique called functional magnetic resonance imagining (fMRI) to understand which brain regions are "active," or being used more in comparison to a non-boring situation. fMRI works using the properties of the blood flowing throughout the brain. To get an fMRI, a person lies down in a big tube while a large magnet circles around their head. The fMRI machine can sometimes be loud, but it is painless! Scientists who study boredom will often induce state boredom while people are in the fMRI scanner, and then they compare their brain activity to another condition, in which the same people are not bored. For example, they can compare brain activity when people are bored to when they are doing an engaging task that they like or a demanding task that requires them to try hard and pay close attention. So far, researchers have not been able to identify a specific set of brain areas that make up boredom. However, some research points to a part of the brain referred to as the default network [8]. The default network is a set of brain regions that are active when you are thinking about yourself or others, or when you are thinking about the past or imagining the future. Activation of the default network might explain why bored people often let their minds wander and think about other things.

\section{SUMMARY}

Boredom is a negative feeling that most of us experiences daily, but it may also be helpful in some cases. Studying boredom scientifically can help us understand our own behavior and experiences. It is exciting that many scientists are continuing to investigate boredom in our everyday lives and how boredom is manifests in the brain. 
Hopefully we will continue to learn more about the good and bad parts of the boring experience for years to come. For now, enjoy your boredom!

\section{REFERENCES}

1. Eastwood, J. D., Frischen, A., Fenske, M. J., and Smilek, D. 2012. The unengaged mind: defining boredom in terms of attention. Perspect. Psychol. Sci. 7:482-95. doi: 10.1177/1745691612456044

2. Chin, A., Markey, A., Bhargava, S., Kassam, K. S., and Loewenstein, G. 2017. Bored in the USA: experience sampling and boredom in everyday life. Emotion 17:359. doi: 10.1037/emo0000232

3. Goldberg, Y., and Danckert, J. 2013. Traumatic brain injury, boredom and depression. Behav. Sci. 3:434-44. doi: 10.3390/bs3030434

4. Bench, S. W., and Lench, H. C. 2013. On the function of boredom. Behav. Sci. 3:459-72. doi: 10.3390/bs3030459

5. Elpidorou, A. 2017. The good of boredom. Philos. Psychol. 31:323-51. doi: 10.1080/ 09515089.2017.1346240

6. Mills, C., and Christoff, K. 2018. Finding consistency in boredom by appreciating its instability. Trends Cogn. Sci. 22:744-7. doi: 10.1016/j.tics.2018.07.001

7. Farmer, R., and Sundberg, N. D. 1986. Boredom proneness-the development and correlates of a new scale. J. Pers. Assess. 50:4-17. doi: 10.1207/s153277 52jpa5001_2

8. Danckert, J., and Merrifield, C. 2018. Boredom, sustained attention and the default mode network. Exp. Brain Res. 236:2507-18. doi: 10.1007/s00221016-4617-5

SUBMITTED: 01 May 2020; ACCEPTED: 30 November 2020; PUBLISHED ONLINE: 16 December 2020.

EDITED BY: Athina Tzovara, University of California, Berkeley, United States

CITATION: Mills C and McGrath C (2020) A Boring Overview. Front. Young Minds 8:558229. doi: 10.3389/frym.2020.558229

CONFLICT OF INTEREST: The authors declare that the research was conducted in the absence of any commercial or financial relationships that could be construed as a potential conflict of interest.

COPYRIGHT () 2020 Mills and McGrath. This is an open-access article distributed under the terms of the Creative Commons Attribution License (CC BY). The use, distribution or reproduction in other forums is permitted, provided the original author(s) and the copyright owner(s) are credited and that the original publication in this journal is cited, in accordance with accepted academic practice. No use, distribution or reproduction is permitted which does not comply with these terms. 

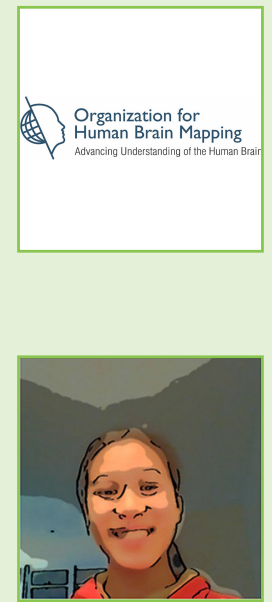

\section{YOUNG REVIEWERS}

\section{ORGANIZATION FOR HUMAN BRAIN MAPPING, AGES: 8-15}

As part of the Kids Live Review Event at OHBM 2020, Adrian, Louie, Pinaki, Reina, and Tian, grilled the scientists on their work in front of an audience. This group of elite reviewers provided pointed feedback that improved the quality of each of these papers, ranging from boredom, irritability, and social learning, to brain surgeries and Alzheimer's disease.

\section{TIAN, AGE: 14}

I am very curious, and I love to learn about humans and our brains because they are so complex and interesting. I also enjoy playing sports with my friends.

\section{AUTHORS}

\section{CAITLIN MILLS}

Caitlin Mills is an Assistant Professor in the Department of Psychology at the University of New Hampshire. Her research focuses on the correlates and consequences of mind-wandering, boredom, and other states that occur during complex learning. *caitlin.mills@unh.edu

\section{CATHERINE MCGRATH}

Catherine McGrath graduated from the University of New Hampshire Honor's Program in 2020. She is currently a post-baccalaureate research assistant in the Affect, Computation, and Cognition Lab at the University of New Hampshire. *cam1064@unh.edu 